\title{
Airports Architectural Design Solutions and New Design Technologies
}

\author{
A. A. Elkady ${ }^{*}$, B. Sh. Ismael ${ }^{* *}$
}

\begin{abstract}
Transportation buildings are interesting applications of architectural design and of which airports are important types. According to the user's requirements, airports design needs different types of architectural solutions. User may be pedestrian passenger (VIP Ordinary people - Trading company's employees), pilots, navigators, Airport teams of work, or a user on Aircraft, Car, Truck and some times railway or Underground Metro; all those need special architectural treatment for each type of spaces and circulation solutions.
\end{abstract}

Keywords: Circulation Solutions, Architectural spaces treatments.

\section{Circulation control in Airports:}

Circulation is the way or path that user walks through to reach a particular place; this path should have a specific design with respect to relationship between spaces and its uses, preventing cross circulation with a suitable width, length, slope, lighting...etc

The main concern of architectural design is to create comfortable spaces this is to accommodate user requirements what could save effort and time. There are many ways of architectural design used to lead Airports users to follow a particular path which are recommended to save effort and time. The characteristics of vehicles, both ground and air, have a large influence on planning, that vehicles (private cars- vans - buses - trucks...) are used on landside and airside. The passenger and shipper of goods are interested in the overall travel time, not just the duration of the air journey. For this reason, access to air port is an essential consideration in planning. [R1]

Many different types of studies are performed in airport planning. These include studies related to facility planning, financial planning, traffic and markets, environmental...etc; however, each of these studies can usually be classified as being one of three levels: the system planning level, the master planning or the project planning level. [R1].

\footnotetext{
*Egyptian Armed Forces, amadelelkadi@ hotmail.com

*** Egyptian Armed Forces, bahaa.shawky@yahoo.com 


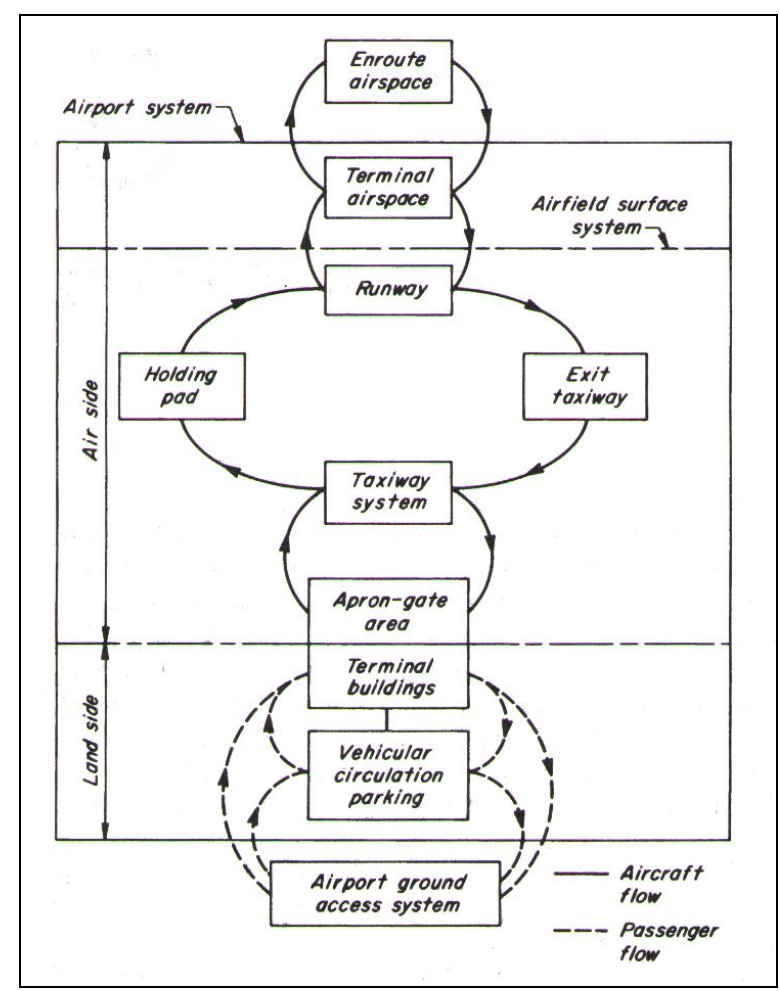

Components of Airport system [R1]

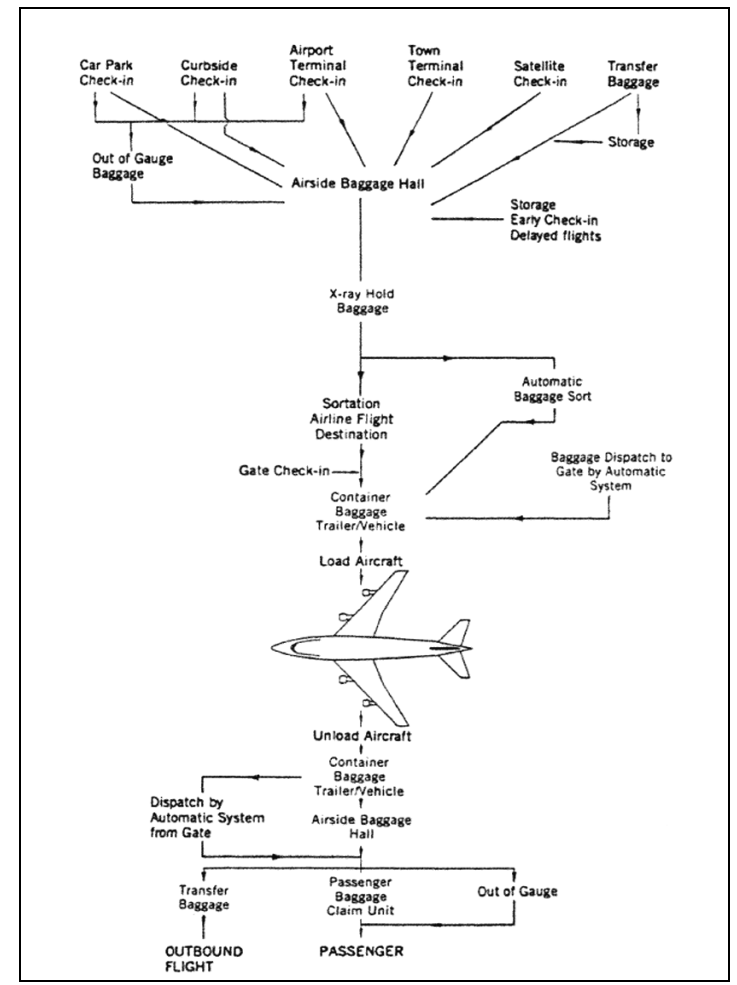

Loading \& unloading sequence [R2]

In airport it is to be considered the requirements of aircrafts as a major concern and other means that serve it (trucks, cars, mechanical equipments and some times railways or metros or harbor if the airport were in a node of transportation). To organize movement of each user preventing cross circulation, there is some solutions and treatments such as:

1) Limitation of user movement through a particular path.

2) Calling user attention means of guide.

3) Paths and spaces reduction.

4) Using printed maps.

5) Using announced instructions.

6) Using written instructions.

Some of these solutions are performed by the airport administrators, the rest of these solutions are performed by designer architectural treatments.

\subsection{Limitation of user movement through a particular path:}

Airport designer use some architectural treatments to make user follow a particular path in order to differentiate between different kinds of circulation, separating spaces by: levels, gates, partitions, paling, walls (solid, voided, curtain walls) separating zones in case that user is a pedestrian, and using planning elements such as roads (width, pattern, materials), bridges, landscaping green areas when user is on a craft, car or mechanical equipment. 


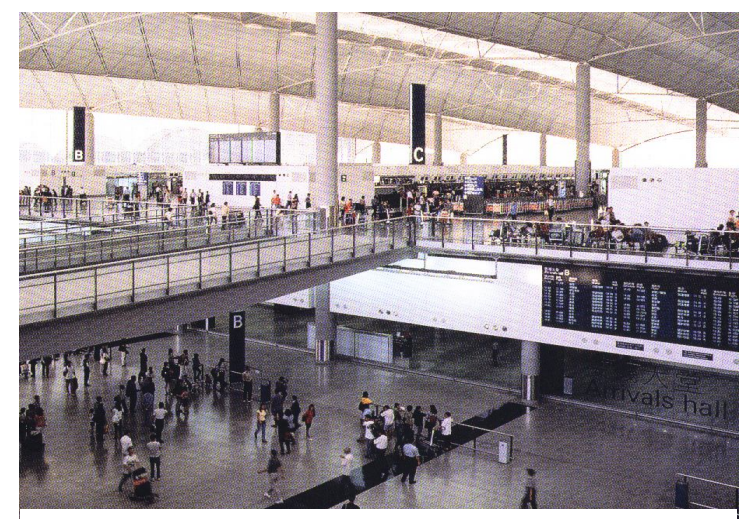

Using levels \& bridges to separate user paths - Hong Kong international Airport China [R3]

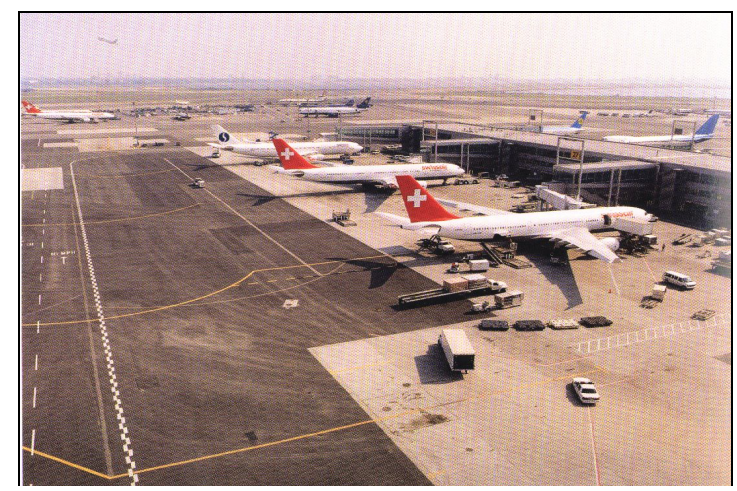

Separating by material \& pattern terminal 4 John F.Kennedy Int. Airport New York [R3]

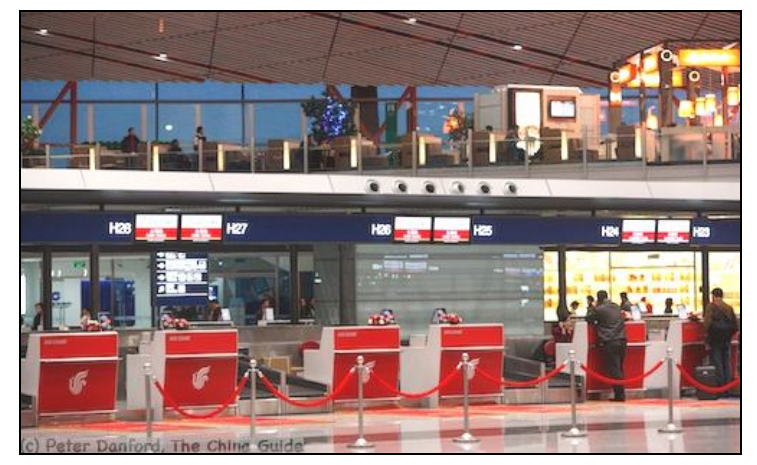

Beijing airport new terminal 3 Check in counters separation using paling

Image from - www.thebeijingguide.com

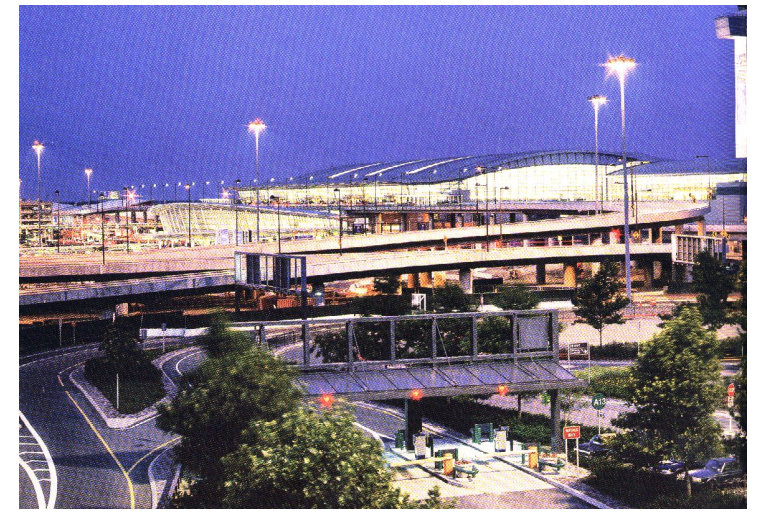

Separating by level - Terminal 4 John F .Kennedy International Airport New York [R3]

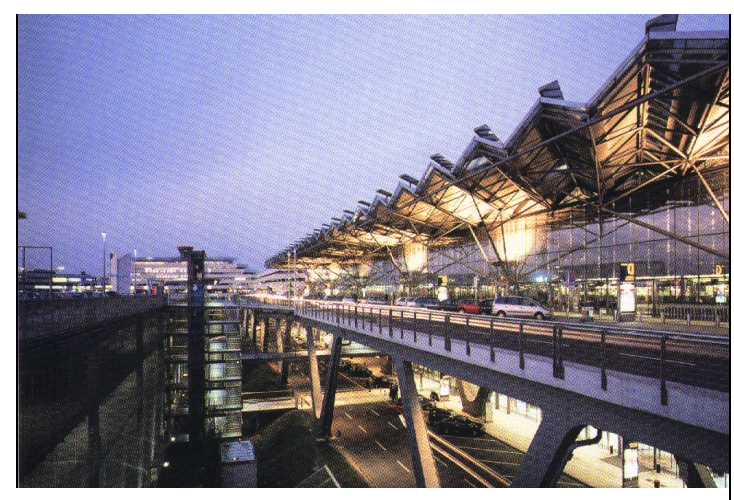

Separating by levels \& bridges -Terminal 2 Cologne - Bonn Airport Germany [R3]

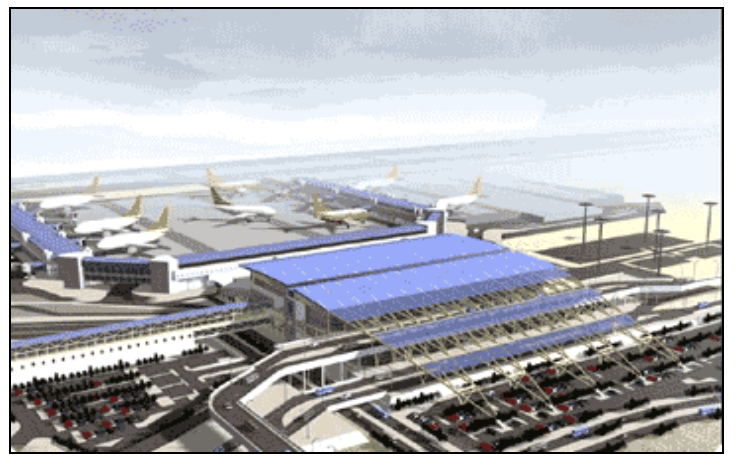

Cairo Terminal Building 3 - separation of roads using levels

Image from - www.cairo-airport.com

\subsection{Calling user attention means of guide:}

In this type of circulation control Architectural items are to be used to call user attention such as different colors, illumination at night, drawings items (lines, signs, maps). These types is widely used specially for wide spaces and large dimensions, like lights at night, lines and signs on the runway to call pilot's attention from large distances to prevent accidents while landing. 


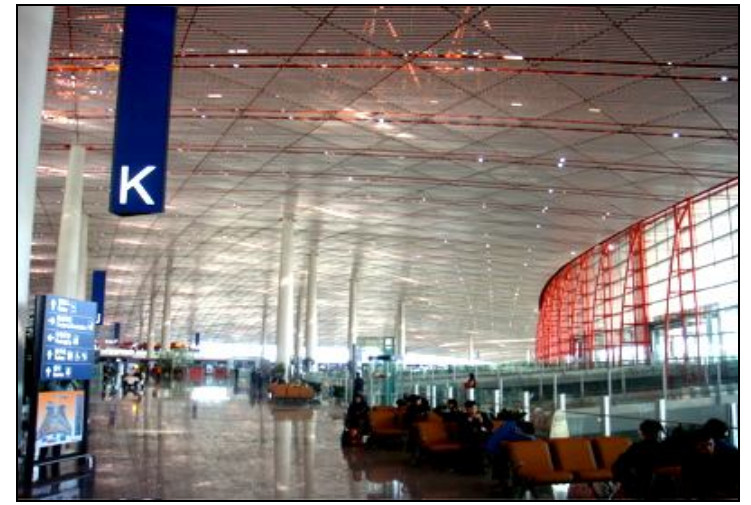

Beijing International airport terminal 3 Naming zones by letters Image from - www.cnreviews.com

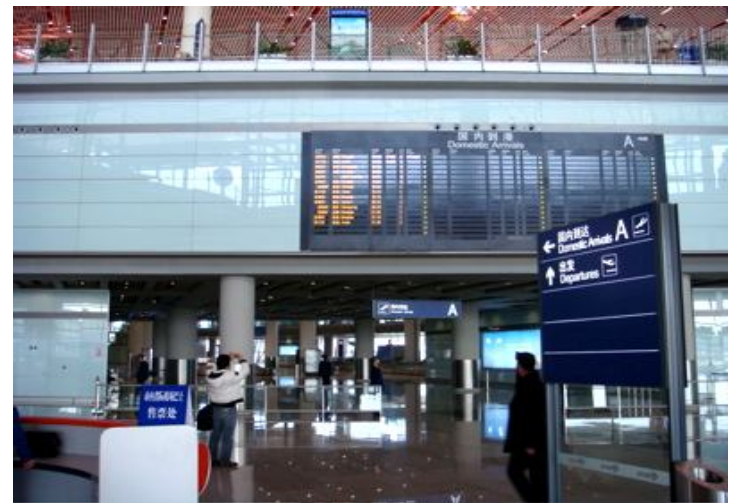

Beijing International airport terminal 3 showing direction using signs Image from - www.cnreviews.com
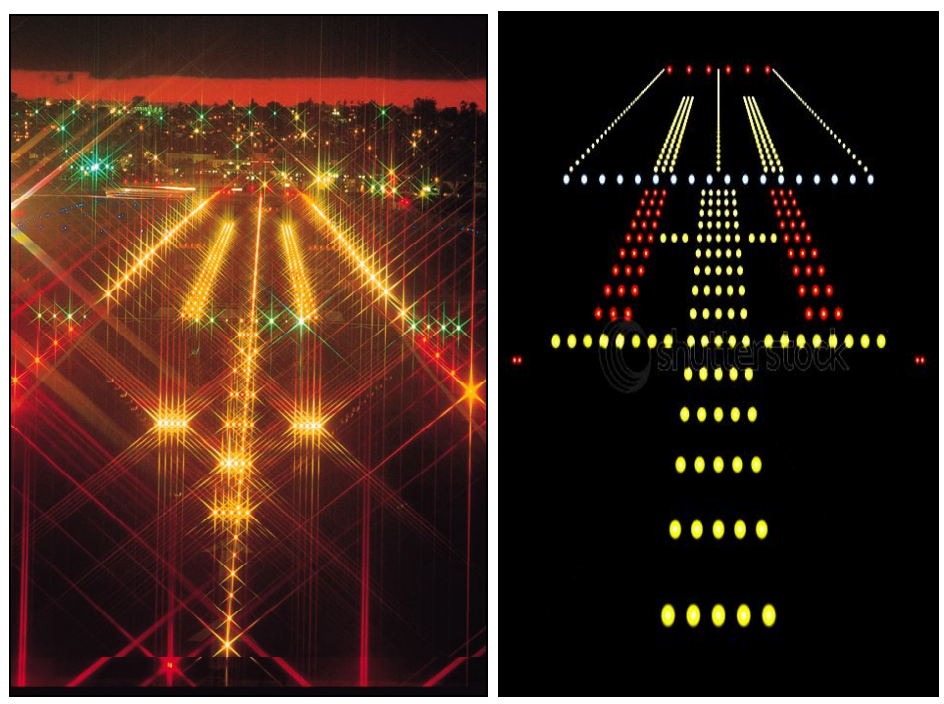

Calling pilot attention using Runway lights At night

Image from - www.shutterstock.com

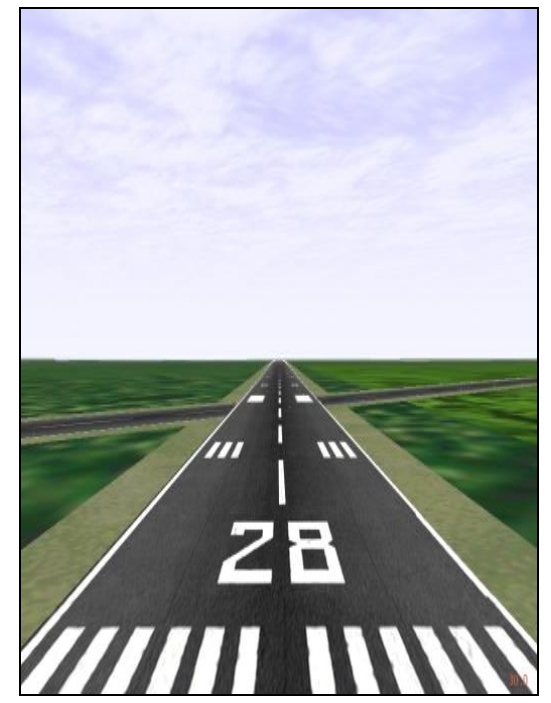

Calling pilot attention using Lines on the Runway

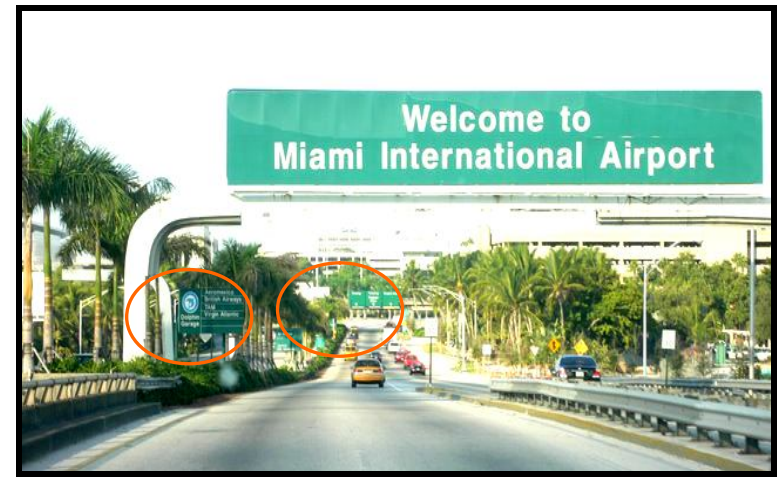

Calling user attention on road to airport Using signs - Miami Int. Airport Image from - www.hotelstravel.com

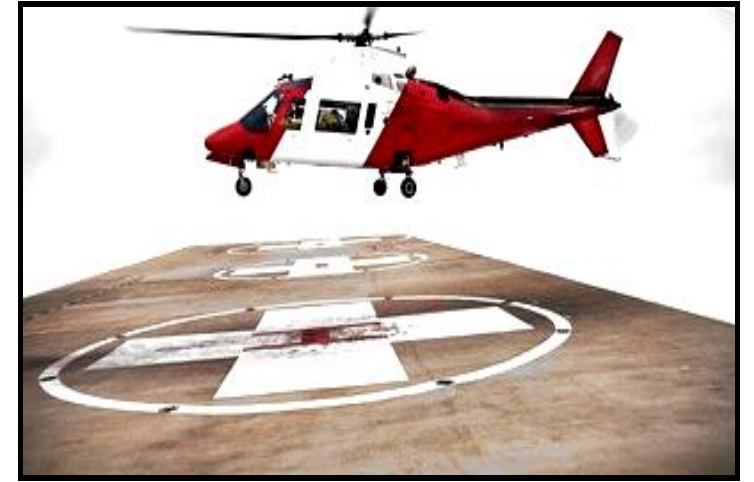

Calling Helicopter pilot's attention to landing position using drawings on land Image from - www.hotelstravel.com 


\subsection{Paths and spaces reduction:}

Large spaces and long paths cause the user to lose his path and direction especially if it was his first visit. To prevent path loss, using a simple design or planning separate zones with respect to its function to made it easy for users to find path, such as separating trading, departure, arrival and VIP zones to be in a linear sequence design or separated buildings.

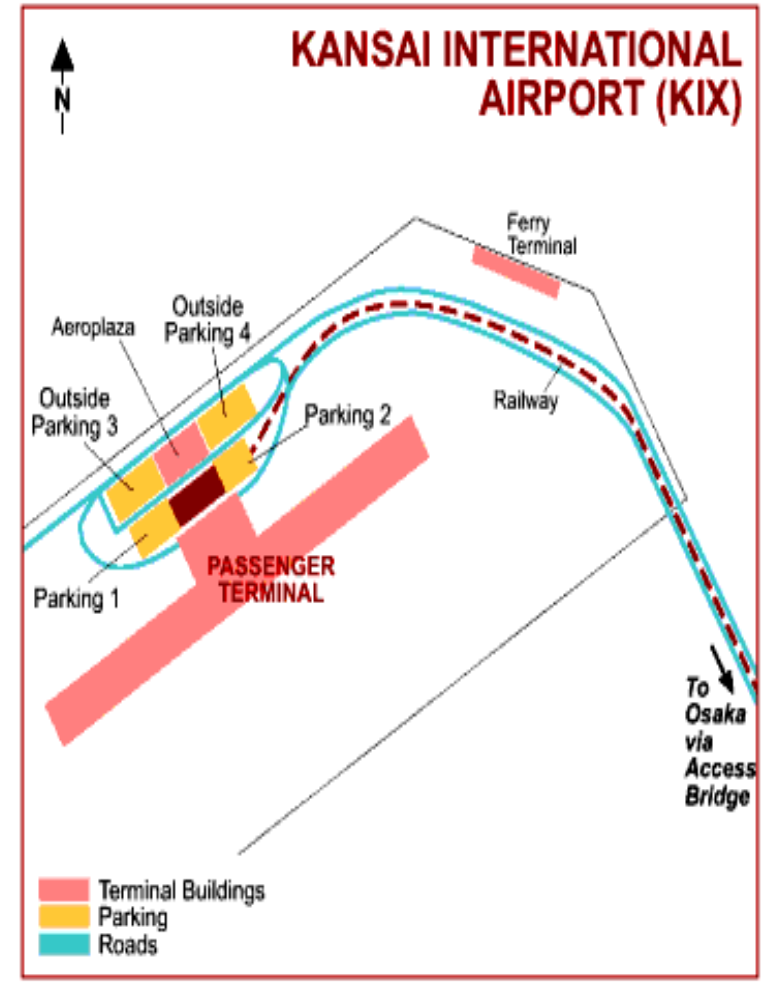

Kansai International Airport (Osaka) Separating zones

Image from - www.sheapflights.com

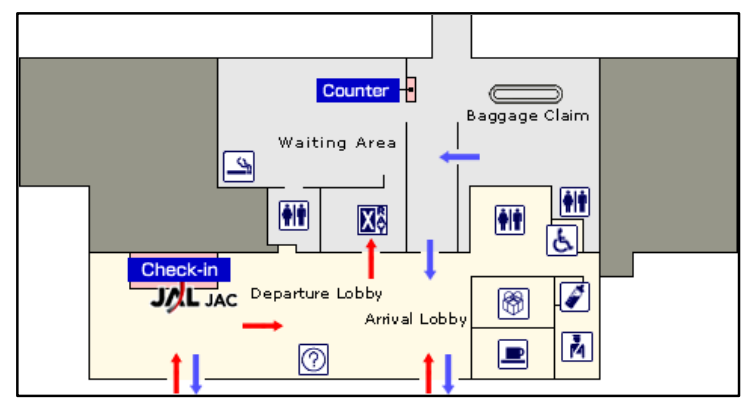

Oki airport in Japan - using linear design Image from - www.jal.co.jp

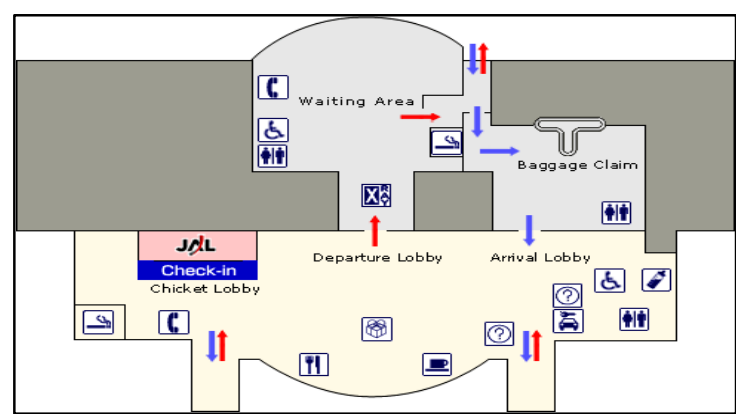

Ttanegashima airport in Japan - using short path Image from - www.jal.co.jp

In Kansai airport, Osaka, Japan a linear design for passenger terminal was used to make the path to the airplane is short as possible.

A continuous airport system planning process is needed to specify the requirements of air transportation with respect to deferent changes in aviation demands, community policies, new technologies and other factors need the timing of facility improvements. In airport system planning process, the overall objective of establishing and maintaining a continuous airport planning process is to insure that the airport system plan remains responsive to public needs. Specific objectives associated with the continuous airport system planning such as development of a continuous mechanism for insuring the interchange of information between the system planning and the master planning process. [R1] 


\subsection{Using signposts, maps or written instruction:}

There are many other methods that used to help user finding his path such as using a printed maps of the airport, or helping user with announced information's in different languages, or by using a printed items and instructions on the user tickets to make it easy for any one work in the airport to help tickets owner.

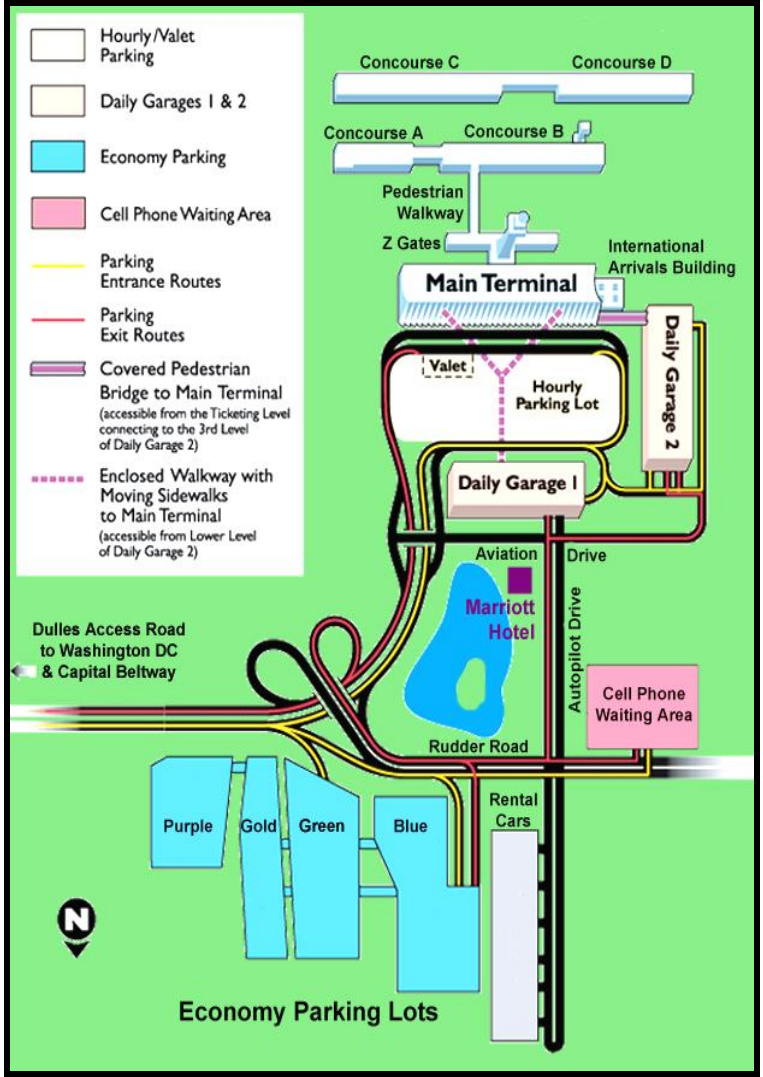

Dulles airport Map on a web site

To help users of airport

Image from - www.visitingdc.com

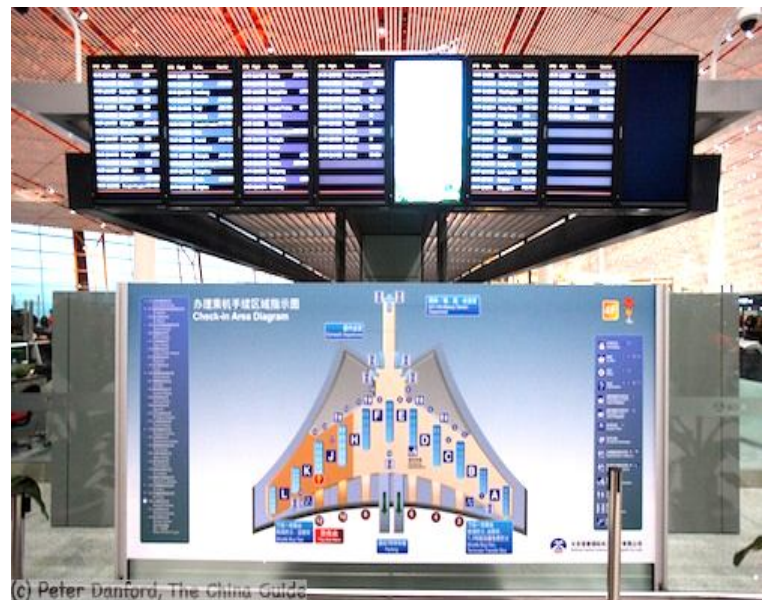

Beijing Capital Airport new terminal 3

Using map to help user

Image from - www.thebeijingguide.com

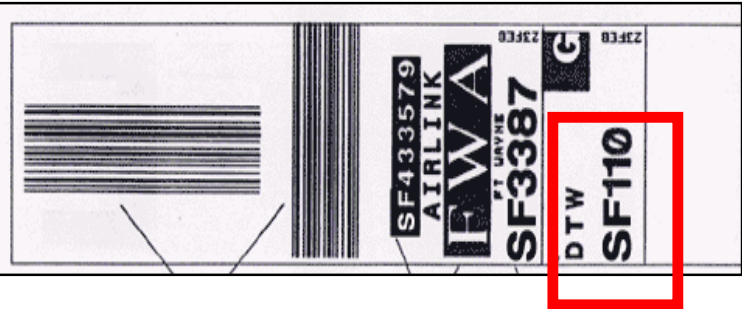

Flights are listed in a part of the ticket (DTW = Detroit, Michigan).

Image from - www.virtualskies.arc.nasa.gov

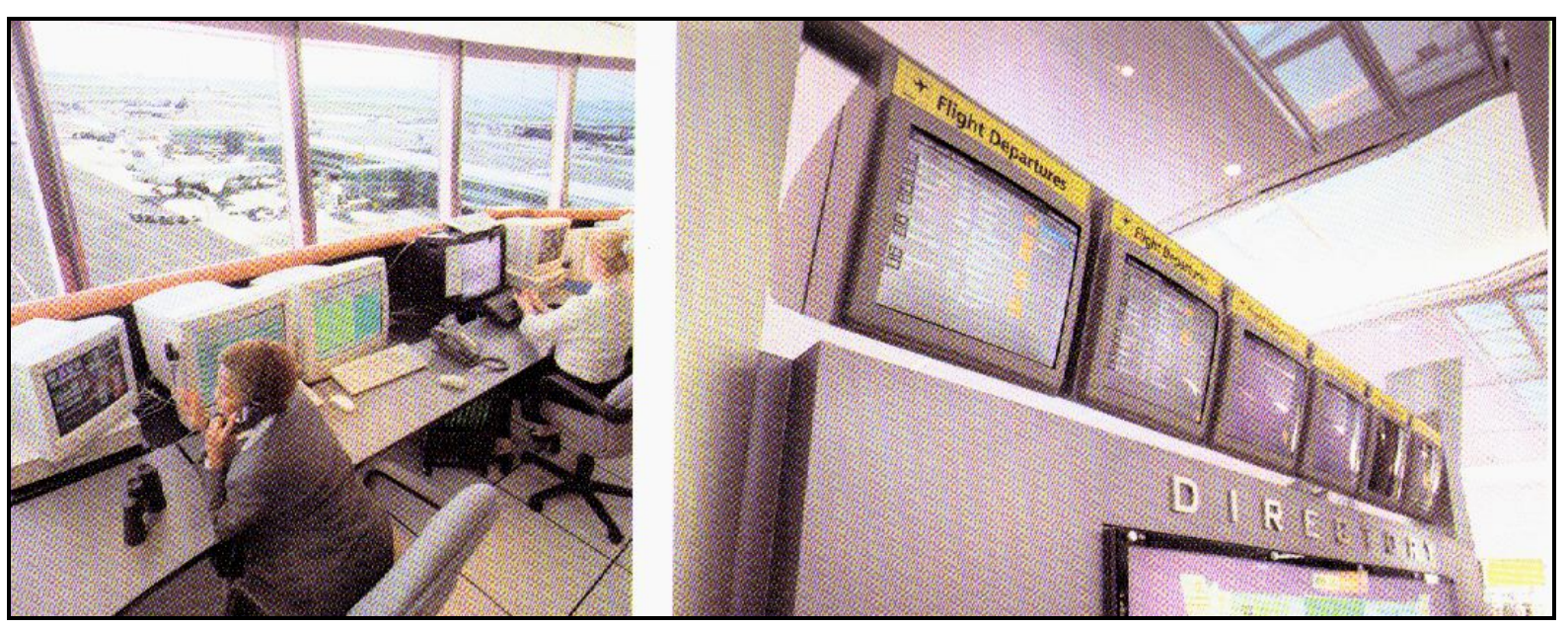

Control system room giving voice announced instructions $\&$ passenger information monitors Terminal 4 John F.Kennedy International Airport - New York [R3] 


\section{Architectural spaces treatments:}

Building architectural designer is to take in his consideration some required studies to help him in the process of design such as:

- Building site study (exterior planning):

- Land nature.

- Traditions \& buildings style.

- Neighborhood.

- Roads.

- Climate (local climate - overall climate - wind direction, speed)...etc.

- Building interior studies required:

- Spatial configuration required.

- Service level.

- Circulation constrains.

- Allowable budget for project to determinate (finishing level - materials - construction technology).

- Standard diminutions of user locomotion and dimensions required for both (humans and Equipments) ...etc.

\subsection{Site architectural treatments:}

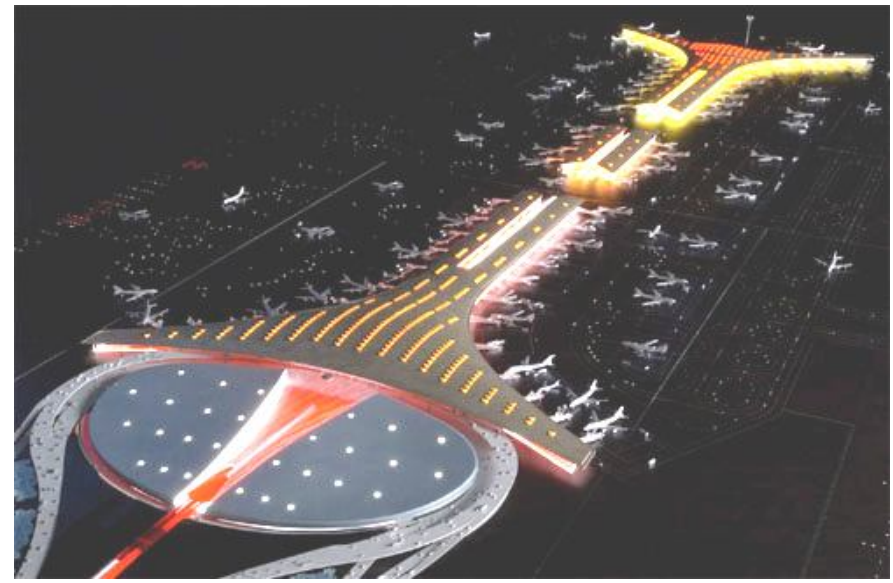

Beijing Capital airport a unique form \& light at night Image from - www.thebeijingguide.com

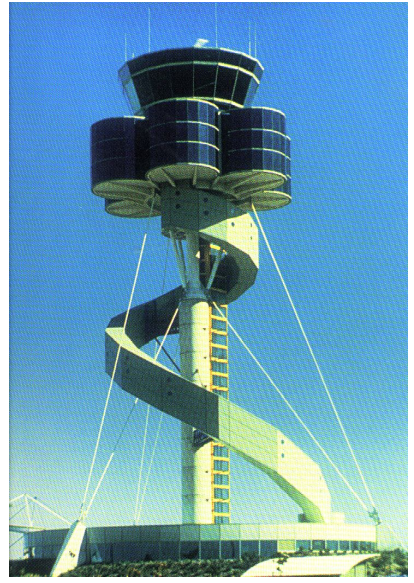

Using control tower as a land mark for the airport - Sydney airport. [R4]
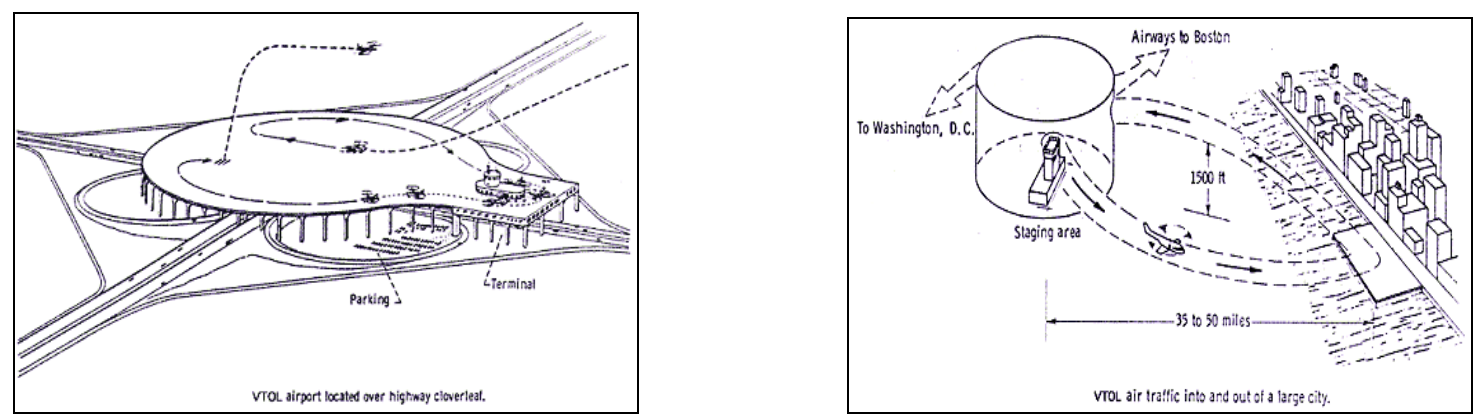

Initial sketches and imaginary solution used to simulate (Site - zoning - building relation with neighbors ...etc) - Image from - www.virtualskies.arc.nasa.gov 
Studies are translated into sketches discussing relationship with neighbor sites and roads forming zoning diagrams to start primary drawings for the project. Through the design stage some problems appear and need to be solved using architectural treatments or solutions which come out with a unique design giving a unique impress that made any one feel astonished and impressed from the first look. The uniqueness of design is to be intended to show the technological development of the country.

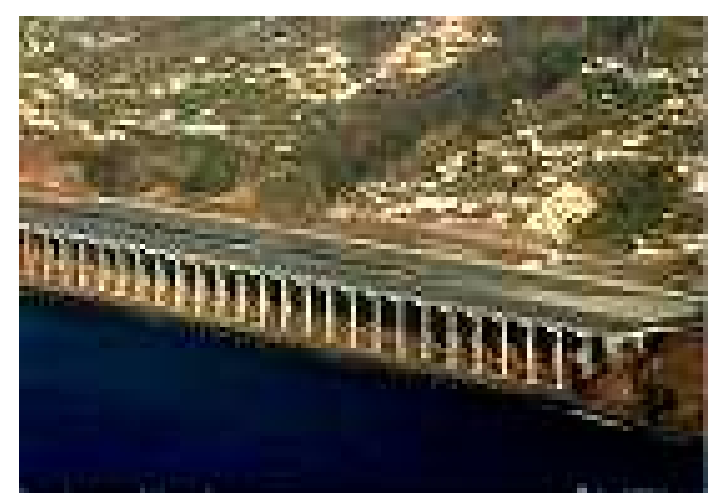

Building a runway on edge of a mountain - cost due to land nature

Image from - www.hotelstravel.com

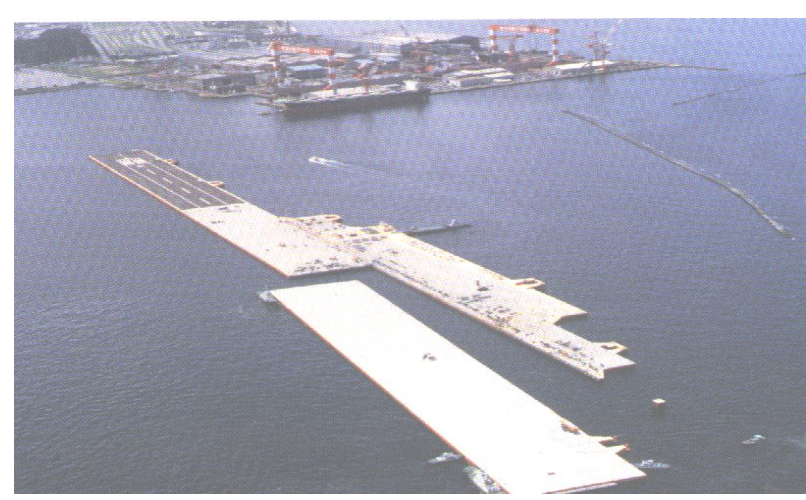

The working prototype of Mega float is assembled In Tokyo bay - at 2000 [R4]

Kansai international airport in Osaka was built on an artificial island in Osaka Bay as a result to the mega floating test. Construction of the island took six years to complete. The last phase to be completed was the construction of a bridge to connect the airport to the mainland. The airport serves approximately 45 airlines. This idea of building an airport on an artificial island gives it a unique character. [R3]

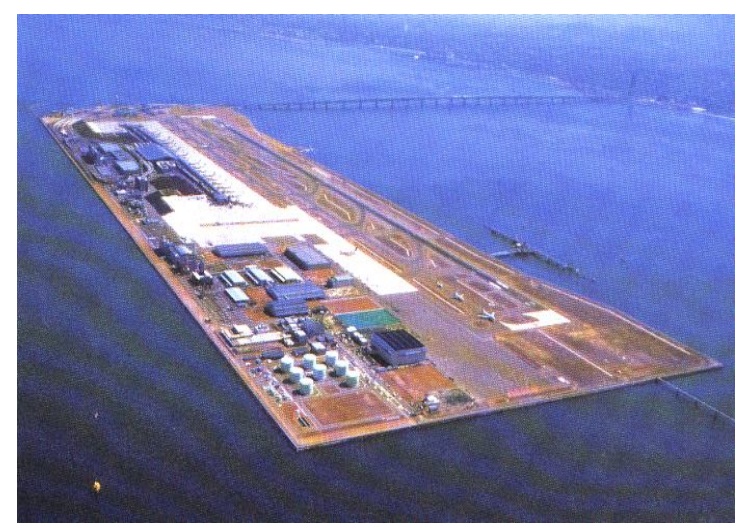

Kansai international airport in Osaka on an artificial island

In Osaka Bay before development [R5]

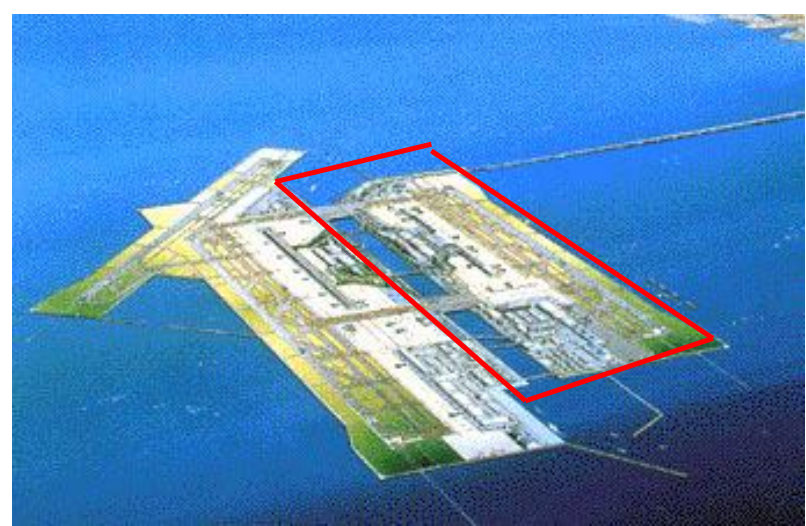

Kansai International airport in Osaka after new developments - line around the old artificial airport Island -I mage from - www.kansi-airport.or.jp

\subsubsection{Items used to deal with site architectural treatments:}

- New construction technologies.

- Site illumination effects at night.

- Using landmarks (statues - towers - high rise structures ...etc)

- Landscaping items (green areas - water pools - bridges -fountains ...etc)

- Side walks, Terraces, Shades... and many other items. 


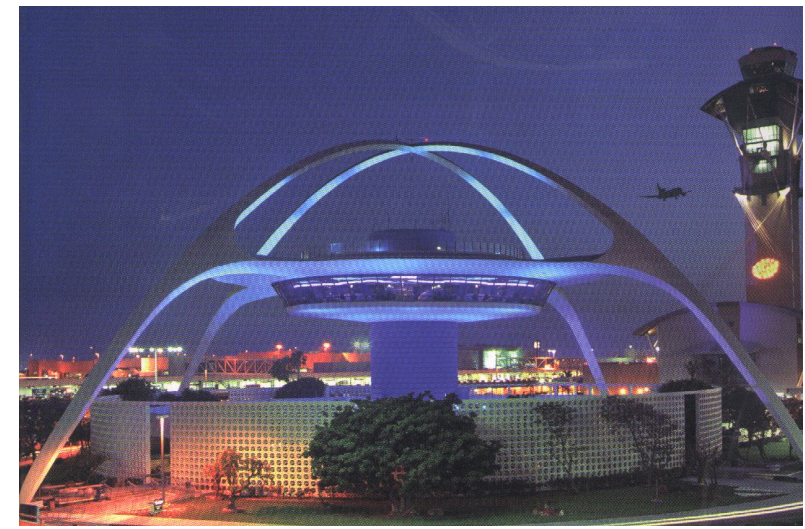

Los Angles international airport Control tower \& airport building a combination of structure [R4]

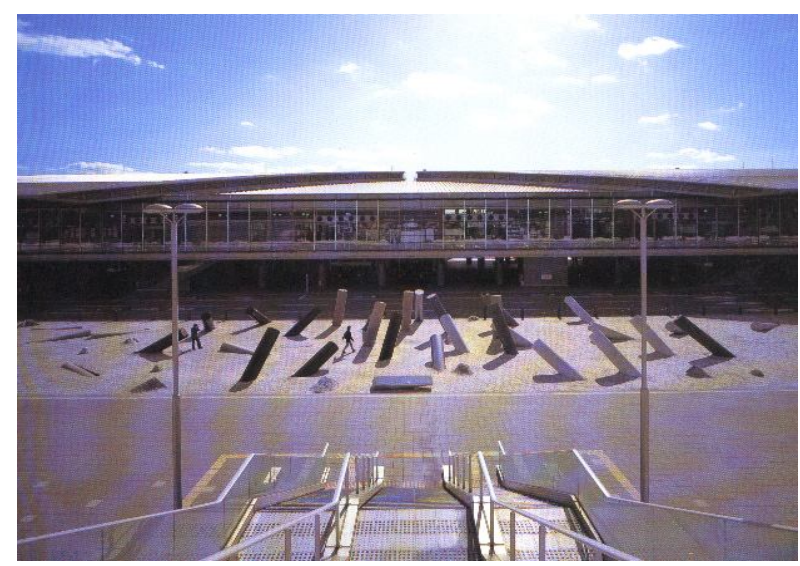

Hiroshima airport - Landscape using Concrete forms. [R5]

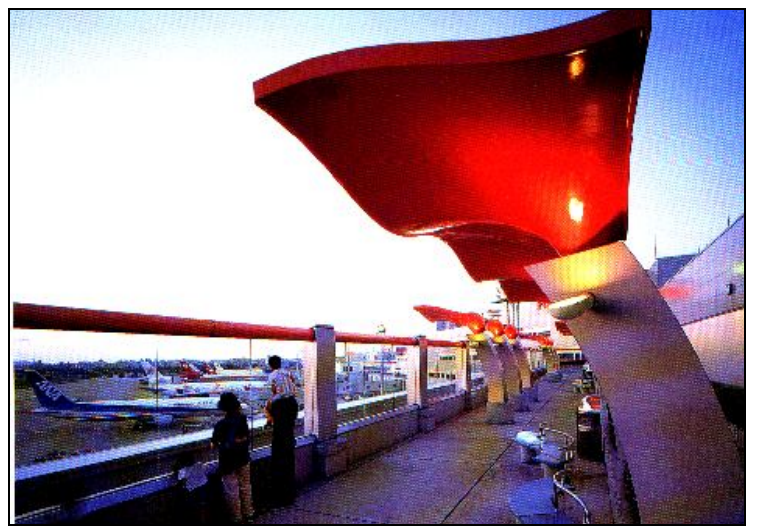

Fukuoka airport in Japan An outside terrace with a curved shaped shade [R5]

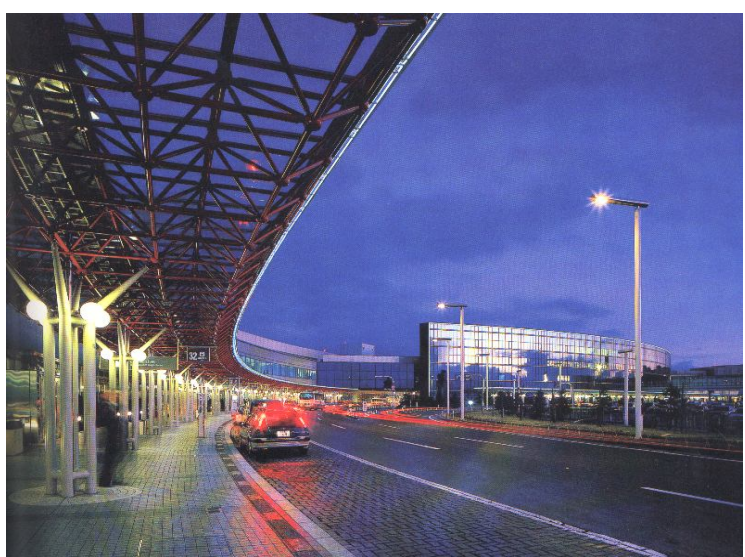

New Chitose airport in Japan

Passenger approach landscape patterns [R5]

\subsection{Interior architectural treatments:}

Architectural treatments for the interior concern the interior design for airport spaces and aircrafts interior spaces design. Seek for user comfort ness, using new materials and creative architectural solutions with new technologies.

\subsubsection{Items used to deal with Interior architectural treatments:}

- New construction technologies.

- Means of illumination effects.

- Using sound effect (echo - water fountains sound...etc)

- Using ventilation effects (hot, cold and warm air - air vents...etc)

- Using imagery items (wall drawings - statues - interior fountains ...etc)

- Using new materials techniques and pattern designs.

- Using panoramic elevators.

- Using civilized \& old traditional styles.

- Terraces, bridges, escalators... and many other items. 


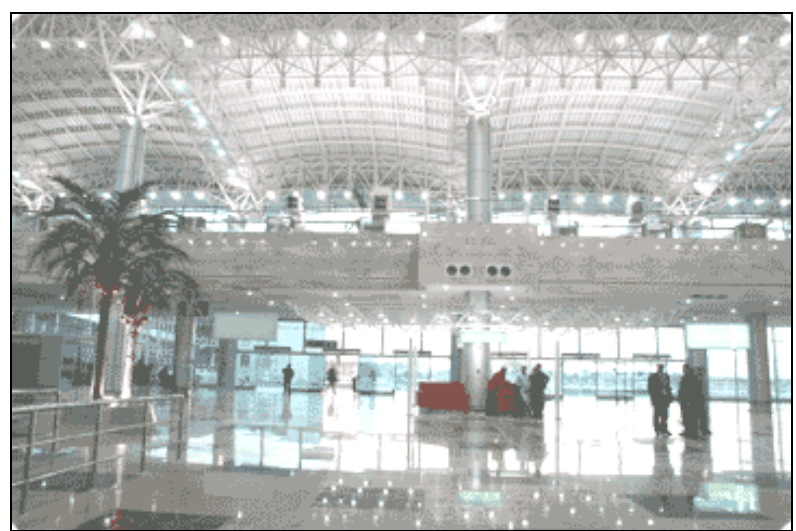

Cairo terminal International Arrival Hall 3 - Wide space required Image from - www.cairo-airport.com

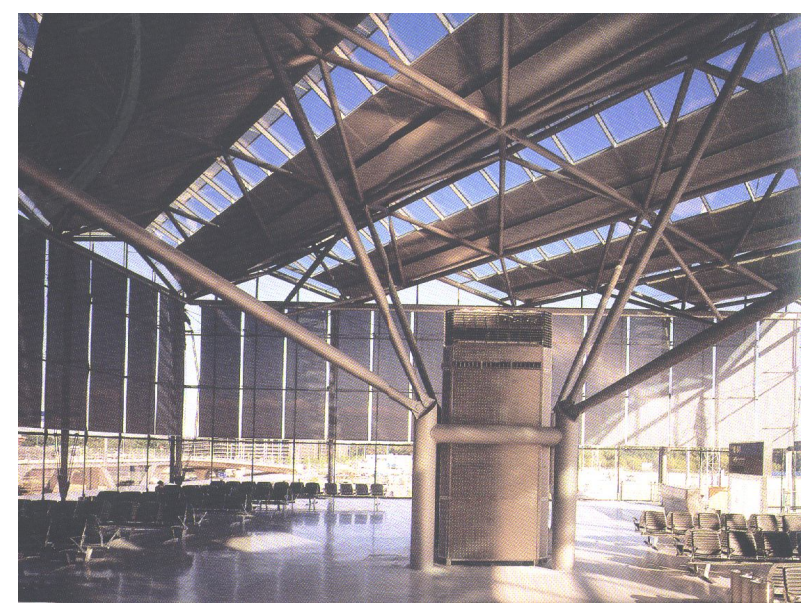

Structure tree columns with large clear spans accommodating Services equipments Terminal 2 Cologne - Bonn Airport Germany [R3]

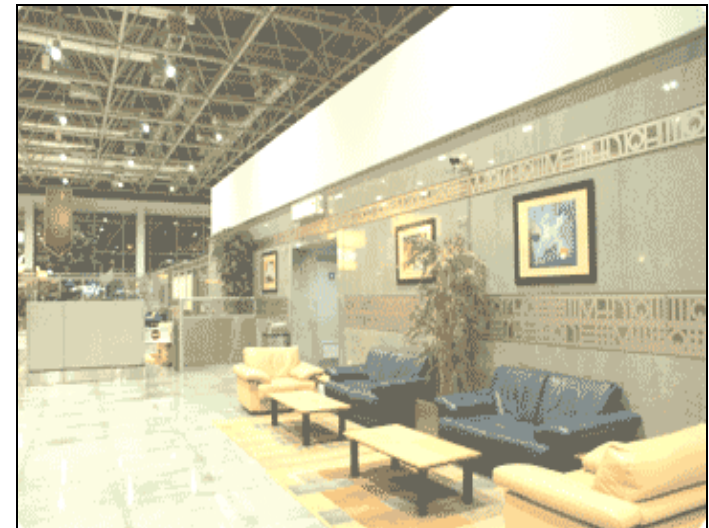

Cairo terminal International Transit \& Transfer Hall - Ancient Egyptian style Image from - www.cairo-airport.com

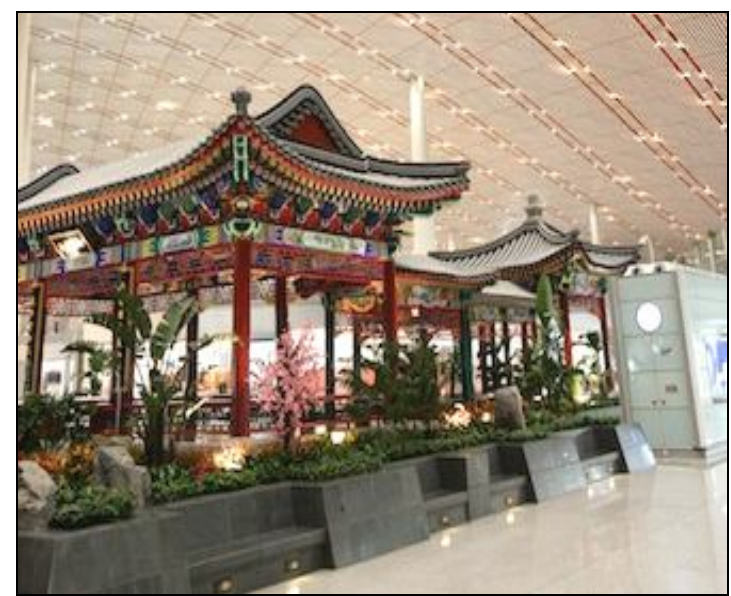

Beijing Capital airport

A touch of traditional architecture Image from - www.thebeijingguide.com

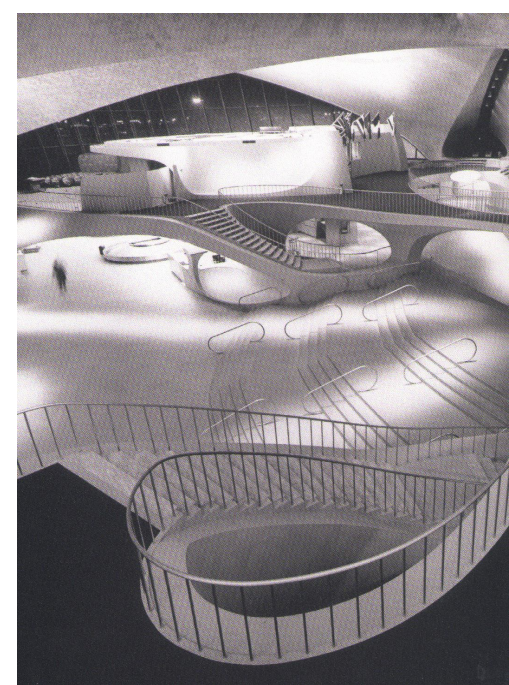

Interior shot in John F Kennedy international sinnonet [D/1

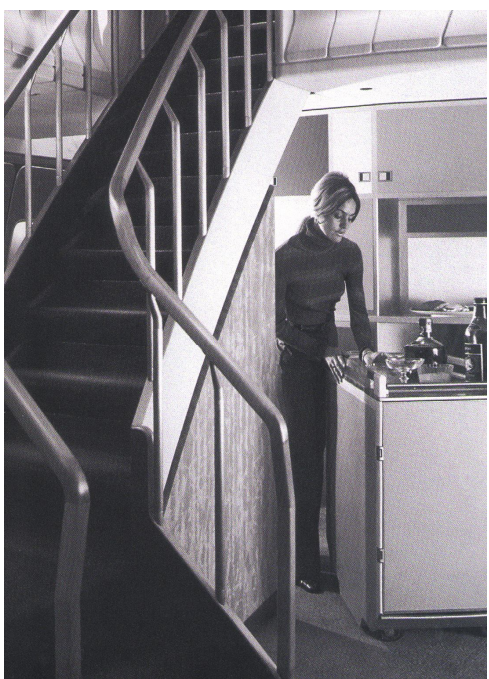

747 The first plane that give considerable scope on interior In an airplane. [R4]

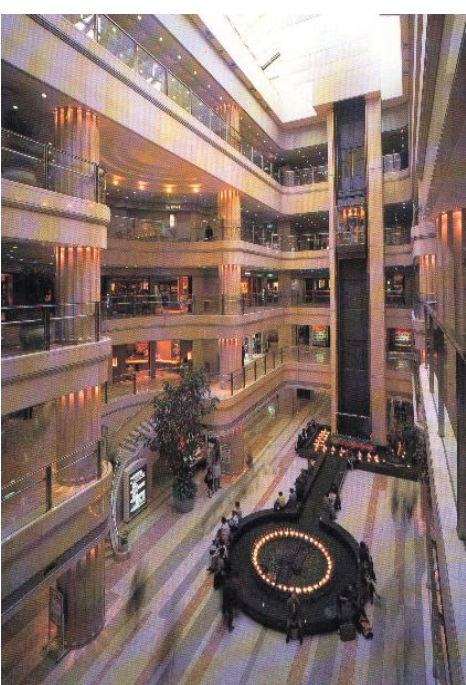

Tokyo International Airport Interior lobby [R5] 

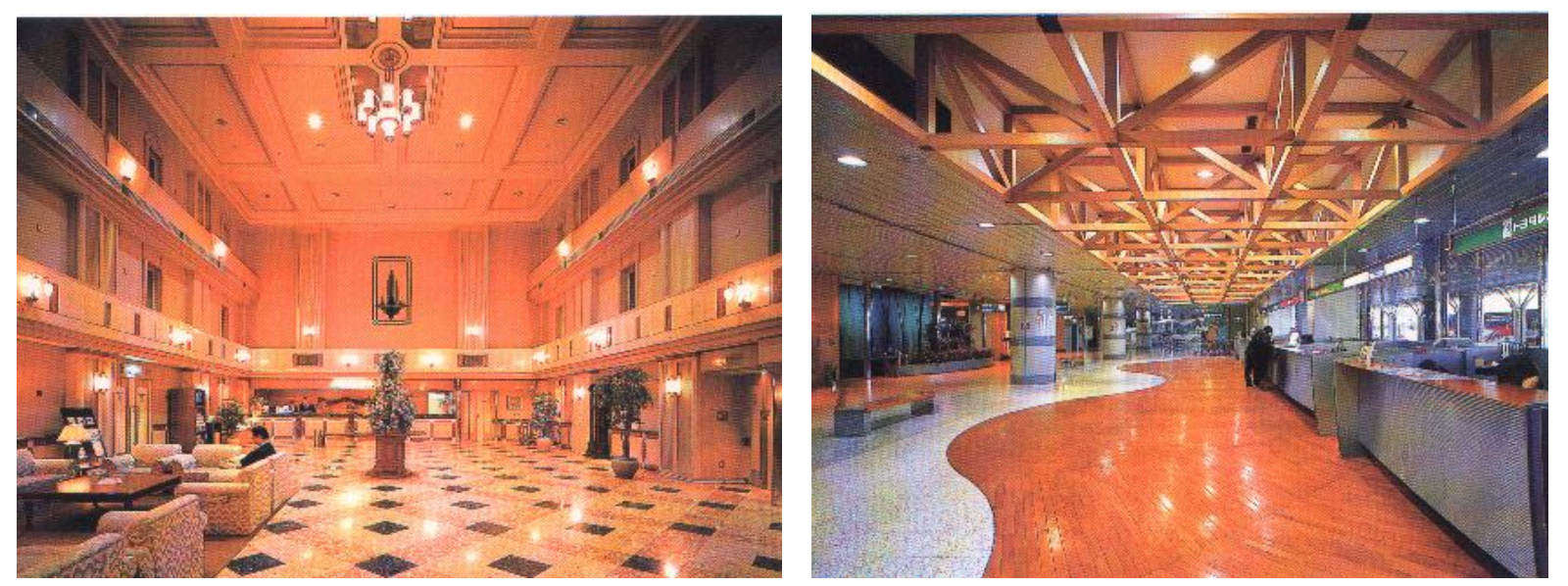

New Chitose airport in Japan - Interior finishes using deferent floor patterns designs

Architectural interior design of aircrafts is an important topic that provide user with all technologies that may make his flight more comfortable and easy as if he were in his home.
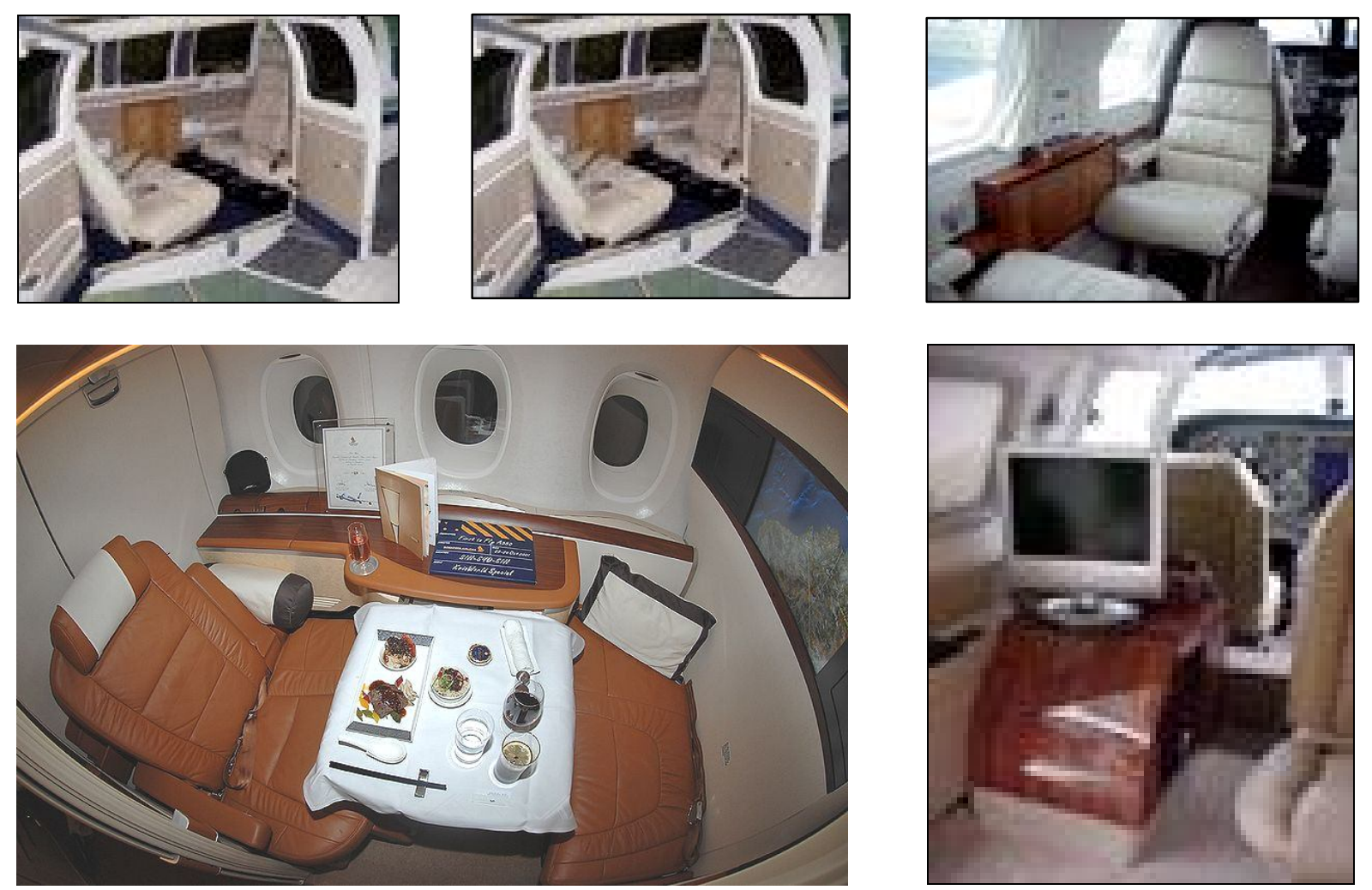

Interior Shots for deferent types of airplanes - seek for comfortable spaces Image from - www.aircraftinteriors.org

When designing aircraft interior we consider all technical installations that may be installed such as (water supply - air conditioning - sanitation - sound systems - TV system telephones ...etc) making places or ducts to be used for wires or ventilation system and suggesting (places of lights - sound distributors - positions of seats - kitchens - bars materials of finishing floors and walls ...etc). 


\section{Conclusion}

Airports architectural design of circulation main purpose is to organize the movement of users to prevent cross circulation and to save both time and effort, according to the requirements of the airport system and user needs. User movement can be organized using new architectural technologies such as new materials and construction techniques. To design a successful circulation there is some items to be covered:

1 The limitation of user movement.

2 Calling attention using visual and sound effects.

3 Reduction of paths and spaces.

Airports architectural design process is divided into two main sections; the first is the exterior design including site plan design, the second is the Interior design including the interior of the airport spaces and the interior of the aircraft. The architectural design process of the airports needs some studies to be applied and treatments to be used which resulted in a unique building construction.

\section{References}

[1] Robert Horonjeff \& Francis X. McKelvey, "Planning \& Design of Airports", $4^{\text {th }}$ Edition, McGraw-Hill, 1994, ISBN 0-07-045345-4.

[2] Norman Ashford \& Paul H. Wright, "Airport Engineering", $3^{\text {rd }}$ Edition, Wiley, New York, 1992, ISBN 0-471-52755-6.

[3] Hugh Collis, "Transport, Engineering and architecture", $1^{\text {st }}$ Edition, Laurence King, 2003, ISBN 1-85669-321-X.

[4] Hugh Pearman, "Air ports a century of Architecture", $1^{\text {st }}$ Edition, Laurence King, 2004, ISBN 1-85669-356-2.

[5] Minoru Takeyama, "Transportation Facilities", 1st edition, Meisei publications, 1997, ISBN 4-938812-26-6. 